\title{
Long-term survival of locally advanced stage III non-small cell lung cancer patients treated with chemoradiotherapy and perspectives for the treatment with immunotherapy
}

\author{
Martina Vrankar, Karmen Stanic \\ Institute of Oncology Ljubljana, Ljubljana, Slovenia
}

Radiol Oncol 2018; 52(3): 281-288.

Received: 22 November 2017

Accepted: 30 November 2017

Correspondence to: Assist. Karmen Stanič, M.D., Ph.D., Institute of Oncology Ljubljana, Zaloška 2, 1000 Ljubljana, Slovenia. Phone: +386 15879 51; Fax: +386 15879 400; E-mail: kstanic@onko-i.si

Disclosure: No potential conflicts of interest were disclosed

\begin{abstract}
Background. Standard treatment for patients with inoperable locally advanced non-small cell lung cancer (NSCLC) is concurrent chemoradiotherapy (CCRT). Five-year overall survival rates range between 15 and $25 \%$, while long term survival data are rarely reported.

Patients and methods. A total of 102 patients with stage III NSCLC treated between September 2005 and November 2010 with induction chemotherapy and CCRT were included in this long term survival analysis. All patients were tested for PD-L1 status and expression of PD-LI was correlated with overall survival (OS), progression free survival (PFS) and toxicities.

Results. The median OS of all patients was 24.8 months (95\% Cl 18.7 to 31.0 ) with 10 year-survival rate of $11.2 \%$. The median OS of patients with PD-L1 expression was 12.1 months (95\% Cl 0.1 to 26.2), while in patients with negative or unknown PD-L1 status was significantly longer, 25.2 months ( $95 \% \mathrm{Cl} 18.9$ to 31.6$), \mathrm{p}=0.005$. The median PFS of all patients was 16.4 months (95\% Cl 13.0 to 19.9). PFS of patients with PD-L1 expression was 10.1 months (95\% $\mathrm{Cl} 0.1$ to 20.4 ) and in patients with negative or unknown PD-L1 status was 17.9 months (95\% Cl 14.2 to 21.7$), p=0.003$.

Conclusions. 10-year overall survival of stage III NSCLC patients after CCRT is $11.2 \%$. PFS and OS differ with regard to PD-L1 status and are significantly shorter for patients with PD-L1 expression. New treatment with check-point inhibitors combined with RT therefore seems reasonable strategy to improve these results.
\end{abstract}

Key words: locally advanced NSCLC; survival; immunotherapy; PD-L1 expression; chemoradiotherapy

\section{Introduction}

Locally advanced non-small cell lung cancer (LANSCLC) patients represent one third of all patients with NSCLC. ${ }^{1}$ Approximately $70 \%$ of NSCLC patients in stage III have inoperable disease. Standard treatment for these patients is concurrent chemoradiotherapy (CCRT). ${ }^{2}$ Five-year overall survival rates of these subgroups are ranging between 15 and $25 \%$. Some centres have reported encouraging five-year survival results of $30 \%$ with trimodality treatment including surgery in selected patients.,
Even by escalation of radiation dose and integration of molecular targeted agents the prognosis of these patients remains poor. ${ }^{5}$ It seems that the plateau has been reached in the treatment of patients with LA-NSCLC with different schedules of radiotherapy (RT) and chemotherapy (ChT), therefore new strategies to improve survival outcomes of these patients are desperately needed.

The programmed cell death 1 (PD-1)/programmed cell death ligand 1 (PD-L1) checkpoint inhibitors demonstrated impressive activity for the treatment of metastatic NSCLC. ${ }^{6-8}$ Several clini- 
cal trials evaluating immunotherapy and RT for NSCLC have focused on patients with metastatic disease and this combination showed the synergistic therapeutic effect. ${ }^{9}$ Recently, for the first time in LA-NSCLC, adjuvant treatment with anti PD-L1 immunotherapy after standard treatment with CCRT showed clinically significant improvement in progression-free survival. Consolidation treatment with durvalumab did not require PD-L1 testing in this study. ${ }^{10}$

It is unclear whether PD-L1 testing is necessary in this patients setting. However, based on several trials in metastatic patients who responded better to immunotherapy, if the expression of PD-L1 was higher, it seems reasonable to collect as many information on expression of PD-L1 as possible.

In light of this new therapeutic options we report here almost 10-year overall survival rate of a prospective phase II study in LA-NSCLC treated with induction ChT and CCRT, in whom additional PD-L1 testing was performed. We discuss the perspectives of new treatment strategies by adding immunotherapy to the standard treatment.

\section{Patients and methods}

Patients with inoperable stage III LA- NSCLC treated with combined induction ChT and CCRT were included in this analysis. All patients were without relevant contraindications and treated with curative intent.

All patients were treated with three cycles of induction ChT followed by RT concurrent with two cycles of ChT. For induction ChT we compared two different dosages and time of application for gemcitabine: the standard i.v. dose in half hour and one fifth of the standard dose in prolonged 6-hours i.v. infusion on days 1 and 8 . To all patients cisplatin on day 2 was administered. All patients continued treatment within 8 days after the last cycle of ChT with RT concurrent with cisplatin and etoposide on days 1-5 and 29-33. ${ }^{11} \mathrm{RT}$ was administered with a linear accelerator photon beam of 5-10 MV in 2 Gy fractions to a total dose of 60-66 Gy. Threedimensional CT-based conformal radiation therapy was used for planning for all patients and no elective nodal volumes were included. Dosimetric parameters were generated from the dose-volume histogram (DVH).

Toxicities were assessed according to Common Terminology Criteria for Adverse Events (CTCAE) version 3.0.12 The responses were evaluated according to Response Evaluation Criteria in Solid
Tumour (RECIST) criteria version 1.0. ${ }^{13}$ After completion of the treatment, all patients were closely followed-up.

Retrospectively, PD-L1 testing was performed from archived tumour tissue samples, collected before any tumour directed treatment. Staining threshold on either tumour cells or tumour infiltrating immune cells for PD-L1 positivity was set at $5 \%$ or higher. Ventana monoclonal antibody and an automated staining platform was used as described in our previous report. ${ }^{14}$

All patients were fully informed and signed the informed consent to participate in the trial. The protocol was approved by the Institutional Review Board (Institute of Oncology, Ljubljana) and by the National Committee for Medical Ethics, Ministry of Health, Republic of Slovenia.

\section{Statistical analysis}

The primary endpoints of this retrospective analysis were 10-year overall survival (OS) and OS with respect to PD-L1 expression. Secondary endpoints were progression-free survival (PFS) and long term update of safety profile.

OS was calculated as the time from the start of the treatment to death from any cause. PFS was defined as the time from the beginning of treatment to disease progression or death. Censoring was defined as the time from the beginning of treatment to the last contact with the patient and for alive patients, as the time from the beginning of treatment to the end of follow-up (October 2017).

OS and PFS curves were estimated by using Kaplan-Meier method and log-rank test. Chi-square test was used to compare distribution of discrete variable values between the two arms. Mann-Whitney $\mathrm{U}$ test was used to compare continuous variables. Z-test for the equality between two proportions was used to evaluate the difference between proportions of patients between arms. A p-value less than 0.05 was considered statistically significant.

\section{Results}

\section{Patient characteristics}

A total of 102 patients treated between September 2005 and November 2010 were included in this analysis. Patients at median age of 57 were mostly men $(78.4 \%)$. More than half of patients (56.4\%) had tumours in stage IIIA and squamous histology (57.8\%). Detailed patient demographics according to PD-L1 expression are listed in Table 1. 


\section{Treatment delivery}

Of all, only $49 \%$ of patients completed all three planned cycles of induction ChT and $45.1 \%$ of patients received 2 cycles of induction ChT. The dose intensity, measured as mean value of percentage of drug administered, was for cisplatin $87 \%$ and for gemcitabine $86.8 \%$. After induction ChT, one patient had pulmectomy. Radical RT was completed in $85.3 \%$ of patients with doses of $\geq 60$ Gy. Both therapy was completed in $52 \%$ of patients and $5.9 \%$ of patients received no concurrent ChT. The main reasons for omitting concurrent $\mathrm{ChT}$ were haematological toxicity and esophagitis.

\section{Toxicity}

Treatment-related acute toxicities of the induction ChT were generally well tolerated and are listed in Table 2. The most common grade 3 or 4 adverse event was neutropenia with $23.5 \%$. No patient with febrile neutropenia was observed. Other grade 3 or 4 adverse events were rare with appearance less than $5 \%$. One patient had grade 4 acute peripheral ischemia leading to amputation. With regard to PD-L1 status there were less thrombocytopenia grade 1,2 in PD-L1 positive patients; however, there was more acute kidney injury among them.

Treatment-related acute toxicities of CCRT were more pronounced and are listed in Table 3. The most common grade 1 and 2 adverse events were anaemia in 95.1\% and esophagitis in 66.3\% of patients. Most expressed grade 3 and 4 adverse events were neutropenia in $28.4 \%$ and esophagitis in $13.9 \%$. With regard to PD-L1 status there was no anaemia grade 3,4 in PD-L1 positive patients. Significantly, more nausea and vomiting grade 3,4 were noticed among patients with PD-L1 expression.

\section{Response and survival}

The median OS of all patients was 24.8 months (95\% CI 18.7-31.0) with 10 year-survival rate of $11.2 \%$ and $1,2,3,5$ year-survival rate were $76.5 \%$, $52.0 \%, 38.2 \%, 22.5 \%$, respectively. At the time of last evaluation in October 2017, fourteen patients were still alive with the median follow-up of 117.5 months, but none with PD-L1 expression (Table 4).

The median OS of patients with PD-L1 expression was 12.1 months (95\% CI 0.1-31.6; $\mathrm{p}=0.005)$. OS data are shown in Figure 1.

The median PFS of all patients was 16.4 months (95\% CI 13.0 to 19.9 ). PFS of patients with PD-L1
TABLE 1. Patients characteristics according to PD-L1 expression

\begin{tabular}{|c|c|c|c|}
\hline & $\begin{array}{l}\text { PD-L1 negative } \\
\text { or unknown } \\
(\mathrm{N}=95)\end{array}$ & $\begin{array}{l}\text { PD-L1 } \\
\text { expression } \\
(\mathrm{N}=7)\end{array}$ & $\begin{array}{c}\text { Total } \\
(\mathrm{N}=102)\end{array}$ \\
\hline \multicolumn{4}{|l|}{ Gender } \\
\hline Male & 74 & 6 & 80 \\
\hline Female & 21 & 1 & 22 \\
\hline \multicolumn{4}{|l|}{ Age } \\
\hline Median & 57 & 59 & 57 \\
\hline Range & $30-77$ & $54-64$ & $30-77$ \\
\hline \multicolumn{4}{|l|}{ ECOG PS } \\
\hline 0 & 82 & 7 & 89 \\
\hline 1 & 13 & 0 & 13 \\
\hline \multicolumn{4}{|l|}{ Histology } \\
\hline Squamous & 53 & 6 & 59 \\
\hline Adeno & 23 & 0 & 23 \\
\hline Large cell & 6 & 0 & 6 \\
\hline Other \& unspecified & 13 & 1 & 14 \\
\hline \multicolumn{4}{|l|}{ Stage } \\
\hline$\| I I A$ & 54 & 4 & 58 \\
\hline IIIB & 41 & 3 & 44 \\
\hline \multicolumn{4}{|l|}{ Inoperable due to } \\
\hline Extent & 93 & 7 & 100 \\
\hline Functional & 1 & 0 & 1 \\
\hline Refuse & 1 & 0 & 1 \\
\hline
\end{tabular}

ECOG PS = Eastern Cooperative Oncology Group performance status; PD-L1 = programmed cell death ligand 1

TABLE 2. Treatment-related toxicities of induction chemotherapy with regard to PD-Ll status

\begin{tabular}{|c|c|c|c|}
\hline & $\begin{array}{c}\text { PD-L1 negative } \\
\text { or unknown } \\
\mathrm{N}=95(\%)\end{array}$ & $\begin{array}{c}\text { PD-L1 } \\
\text { expression } \\
\mathrm{N}=7(\%)\end{array}$ & p \\
\hline \multicolumn{4}{|l|}{ Anaemia } \\
\hline Grade 1, 2 & $87(91.6)$ & $6(85.7)$ & 0.780 \\
\hline Grade 3, 4 & $1(1.1)$ & 0 & \\
\hline \multicolumn{4}{|l|}{ Neutropenia } \\
\hline Grade 1, 2 & $24(25.5)$ & 0 & 0.168 \\
\hline Grade 3, 4 & $23(24.2)$ & $1(14.3)$ & \\
\hline \multicolumn{4}{|c|}{ Thrombocytopenia } \\
\hline Grade 1, 2 & $23(24.5)$ & $1(14.3)$ & 0.001 \\
\hline Grade 3, 4 & 0 & $1(14.3)$ & \\
\hline \multicolumn{4}{|c|}{ Acute kidney injury } \\
\hline Grade 1, 2 & $30(31.6)$ & $5(71.4)$ & 0.045 \\
\hline Grade 3, 4 & 0 & 0 & \\
\hline \multicolumn{4}{|c|}{ Nausea/vomiting } \\
\hline Grade 1, 2 & $34(35.8)$ & $5(71.4)$ & 0.167 \\
\hline Grade 3, 4 & $4(4.3)$ & 0 & \\
\hline
\end{tabular}

PD-L1 = programmed cell death ligand 1 
TABLE 3. Treatment-related toxicities of concurrent chemoradiotherapy (CCRT) with regard to PD-L1 status

\begin{tabular}{|c|c|c|c|c|}
\hline & & $\begin{array}{c}\text { PD-L1 } \\
\text { negative or } \\
\text { unknown } \\
\mathrm{N}=94(\%)\end{array}$ & $\begin{array}{c}\text { PD-L1 } \\
\text { expression } \\
\mathrm{N}=7(\%)\end{array}$ & p \\
\hline \multirow{2}{*}{ Anemia } & Grade 1, 2 & 91 (95.8) & $6(85.7)$ & \multirow[t]{2}{*}{0.001} \\
\hline & Grade 3, 4 & $4(4.3)$ & 0 & \\
\hline \multirow{2}{*}{ Neutropenia } & Grade 1, 2 & $27(28.7)$ & $2(28.6)$ & \multirow[t]{2}{*}{0.171} \\
\hline & Grade 3, 4 & $29(30.5)$ & 0 & \\
\hline \multirow{2}{*}{ Thrombocytopenia } & Grade 1, 2 & $48(50.5)$ & $2(28.6)$ & \multirow[t]{2}{*}{0.357} \\
\hline & Grade 3, 4 & $5(5.3)$ & 0 & \\
\hline \multirow{2}{*}{ Acute kidney injury } & Grade 1, 2 & $35(36.8)$ & $4(57.1)$ & \multirow[t]{2}{*}{0.250} \\
\hline & Grade 3, 4 & 0 & 0 & \\
\hline \multirow{2}{*}{ Nausea/vomiting } & Grade 1, 2 & $16(17.0)$ & 0 & \multirow[t]{2}{*}{0.041} \\
\hline & Grade 3, 4 & $5(5.3)$ & $2(28.6)$ & \\
\hline \multirow{2}{*}{ Esophagitis } & Grade 1, 2 & $63(67.0)$ & $4(57.1)$ & \multirow[t]{2}{*}{0.500} \\
\hline & Grade 3,4 & $12(12.8)$ & $2(28.6)$ & \\
\hline \multirow{2}{*}{ Pneumonitis } & Grade 1, 2 & $5(5.3)$ & 0 & \multirow[t]{2}{*}{0.294} \\
\hline & Grade 3, 4 & $3(3.2)$ & $1(14.3)$ & \\
\hline
\end{tabular}

PD-LI = programmed cell death ligand 1

expression was 10.1 months (95\% CI $0.1-20.4$ ) and in patients with negative or unknown PD-L1 status was 17.9 months (95\% CI 14.2-21.7; $\mathrm{p}=0.003)$ (Figure 2).

\section{Discussion}

This retrospective analysis in LA-NSCLC patients treated with induction ChT and CCRT resulted in median survival of 24.8 months and 10-year overall survival rate of $11.2 \%$. Survival data are excellent and comparable even to reported data from studies with trimodality treatment that include surgery. ${ }^{15}$ Since in Slovenia at the time of the study duration only one radiotherapy centre was active and all candidates for radical treatment were included, the present results represent 10-year national survival data of treatment in locally advanced inoperable NSCLC.

Patients with Stage III NSCLC represent the most diverse group in terms of treatment. Multimodality treatment options include combination of systemic treatment with ChT, RT and surgery. ${ }^{16}$ For inoperable patients, combination of ChT and RT represent the best treatment options. Sequential approach has been proven inferior for survival to concurrent one in meta-analysis. ${ }^{2,17}$ CCRT survival benefit of
$4.5 \%$ at 5 years derived from $6.5 \%$ improved local control while the number of distant metastasis was the same with CCRT and sequential ChT. Therefore, further improvement of overall survival could only be achieved through better control of distant metastasis. Adding ChT, either as induction treatment before RT or as consolidation treatment after RT, has not resulted in desired clinically important improvement of overall survival. ${ }^{18,19}$ Results with novel agents such as thyrosin kinase inhibitors of epidermal growth factor receptor and vascular endothelial growth factor monoclonal antibodies were disappointing. ${ }^{5,20,21} \mathrm{New}$ systemic therapies, including immunotherapy, are hoped to bring brake through results to improve treatment results.

Recently, in the study of consolidation therapy with new PD-L1 monoclonal antibody durvalum$\mathrm{ab}$, 11-month improvement of PFS compared to placebo was reported after definitive CCRT in LA-NSCLC. ${ }^{10}$ This improvement was associated with better local and systemic control. PFS benefit resulted from significantly higher local objective tumour response as well as from significantly better systemic control with improved time to distant metastases and lower frequency of new lesions, including brain metastases. The benefit was observed irrespective of PD-L1 expression before treatment.

The results of improved PFS in patient treated with combination of RT and immunotherapy are not surprising. Many preclinical studies reported synergistic effects and substantial increases in local and systemic tumour control when radiation was combined with checkpoint blockade immunotherapy. Results of a preclinical study by Zeng et al. that observed long-term survival of the mice with intracranial glioma treated with anti-PD-1 monoclonal antibodies plus RT, showed local response as well as systemic immunologic memory in the surviving mice, as they were able to reject a secondary challenge of glioma cells. ${ }^{22}$ Although neither PD-1 blockade nor local RT alone eradicated intracranial gliomas, the combination of both therapies generated durable responses. In a test of immunologic memory, naïve and long-term surviving mice were injected with glioma cells. All naïve mice died from the growth of the challenged glioma cells, whereas mice that received prior treatment with combined regimen rejected the glioma challenge. In this study, the combination therapy induced increased tumour infiltration by CD8+ CTLs and decreased the number of CD4+ Tregs. Similarly, many other investigators reported significantly improved local tumour control when radiotherapy was com- 
TABLE 4. Median overall survival (OS) according to PD-L1 status

\begin{tabular}{lcc}
\hline & $\begin{array}{c}\text { PD-L1 } \\
\text { negative or } \\
\text { unknown } \\
\mathbf{N}=95\end{array}$ & $\begin{array}{c}\text { PD-L1 } \\
\text { expression } \\
\mathbf{N}=7\end{array}$ \\
\hline Median OS (months) & 25.2 & 12.1 \\
1-year OS (\%) & 77.9 & 57.1 \\
2-year OS (\%) & 54.7 & 14.3 \\
3-year OS (\%) & 40.0 & 14.3 \\
4-year OS (\%) & 28.4 & 14.3 \\
5-year OS (\%) & 24.2 & 0 \\
10-year OS (\%) & 12.1 & 0 \\
\hline
\end{tabular}

PD-LI = programmed cell death ligand 1

bined with anti PD-L1 in different animal models. Improved local control and long term survival was associated with increased CD8+T cells. ${ }^{23,24}$ Sharabi et al. also noted enhanced proliferation and activation of endogenous antigen-specific CD8+T cells and effector memory cells in the draining lymph node. ${ }^{25}$ These findings raise the question about the meaning of elective nodal irradiation since it might compromise the development of radiation-induced immune response. Park and colleagues noticed in models of melanoma and renal cell carcinoma that irradiation of one tumour type (renal cell carcino$\mathrm{ma}$ ) induced protective immune responses that did not cross over to other tumour types (melanoma) in the same host. ${ }^{26}$

Radiation alone as a form of local therapy induce tumour cell death by direct DNA damage but also induce immunogenic cancer cell death as a consequence of modulation of multiple molecular signals in the tumour microenvironment that leads to enhanced local and systemic immune response. Radiation has both immunostimulatory and immunosuppressive effects. ${ }^{27}$ The first step in immune response to tumour cells death from radiation is uptake and cross-presentation of tumourderived antigens by dendritic cells (DCs). Besides enhancing the release of autologous neoantigens to the immune system, radiation also affect others mediators and mechanisms that contribute to immune cell death, such as production of type I interferon which is necessary for DC activation, calreticullin translocation, release of nuclear protein high-mobility group box-1 (HMGB1) and adenosine triphosphate (ATP). ${ }^{28}$ Other mediators of immune response enhanced by radiation are major histocompatibility complex (MHC) class I and Fas surface expression that induces programmed cell death. ${ }^{29}$ Radiation also increases the density of

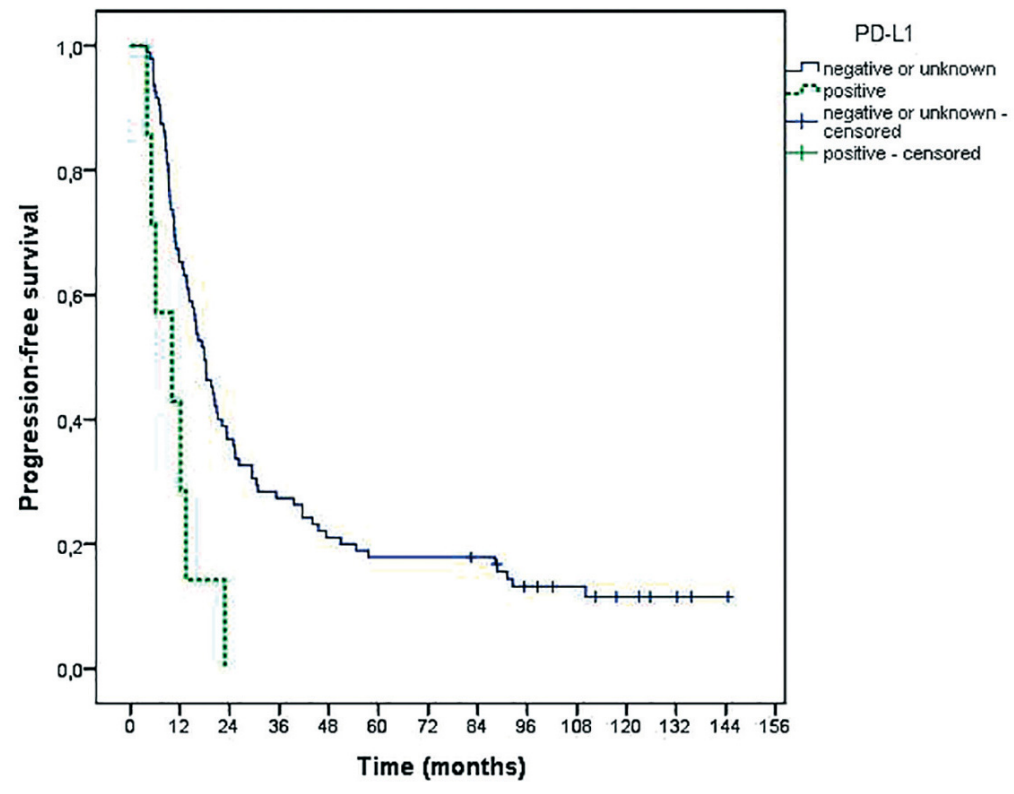

FIGURE 1. Median overall survival (OS) according to PD-L1 status.

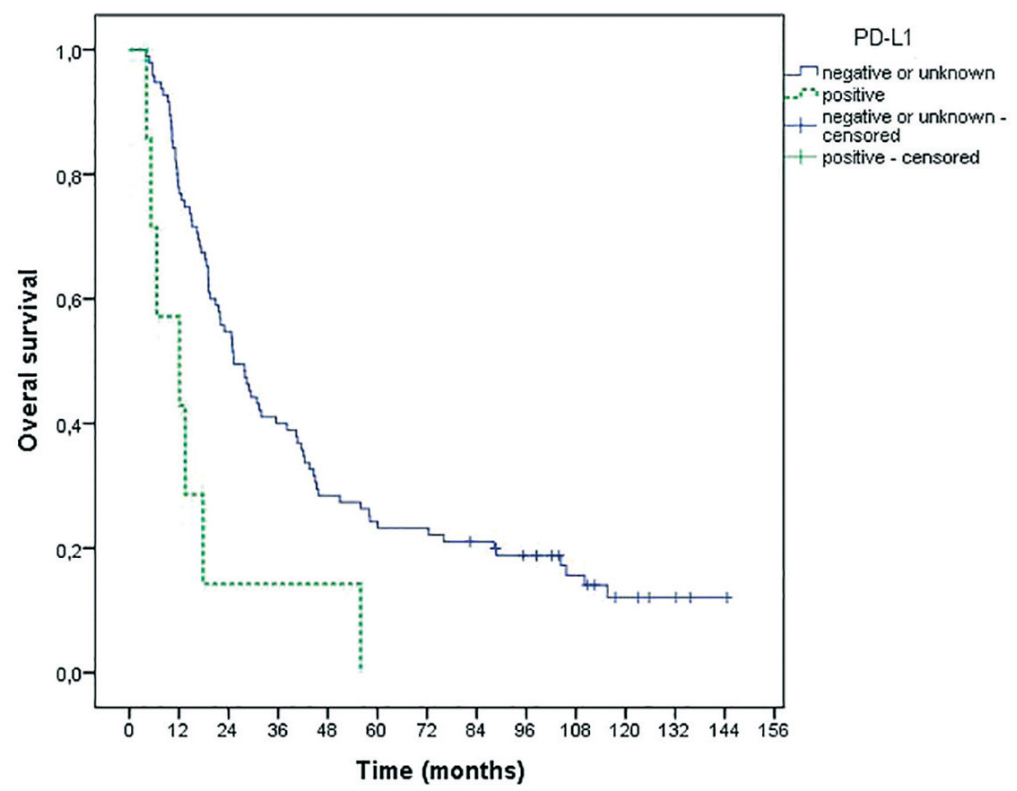

FIGURE 2. Median progression-free survival (PFS) according to PD-L1 status.

tumour-infiltrating lymphocytes. The mechanism is probable multifactorial, two main are proposed: changes in vascular endothelium that increase immune cell extravasation and enhanced expression of chemokine that affect immune cell migration and invasion..$^{30,31}$ On the contrary, radiation can also suppress the immune system by increasing the infiltration of Treg and myeloid-derived suppres- 
sor cells (MDSCs) into the tumour microenvironment. ${ }^{32,33}$ Those are responsible for down regulation of immune response. There are some other factors and pre-existing barriers that are important for tumour rejection and can be modified by radiation such as limited availability of antigen-presenting cells (like DCs). An important barrier for tumour rejection is also the poor homing of effector $\mathrm{T}$ cells in tumours and dysfunctional tumour vasculature which can result in low infiltration by $\mathrm{T}$ cells. Furthermore, number of fractions and dose per fraction also influence the immunogenic response. There are some data to suggest that traditional 2 Gy per fraction has lower impact on immune response than hypofractionation. ${ }^{34}$

One of the important radiation mediated response is also induced expression of PD-L1 in cancer cells and infiltrating myeloid cells. ${ }^{23,24,35}$ PD-L1 expression is being investigated extensively in preclinical and clinical trials but so far results are not consistent since some of them indicate poor prognosis in patients with pretreatment PD-L1 expression and others reported better prognosis than in PD-L1 negative patients. ${ }^{36-39} \mathrm{It}$ is not clear if PD-L1 expression is prognostic or predictive factor of tumour response to treatment including the PD-1/ PD-L1 pathway blockade. In most preclinical studies an increase in PD-L1 expression after radiation was reported. ${ }^{23,24}$ Changes in expression of PD-L1 also were observed after treatment with anti-PDL1 agents. In a study of Herbst et al. the PD-L1 expression increased during immunotherapy, however the levels of pretreatment tumour PD-L1 expression did not correlate with radiographic response. ${ }^{40}$ In recent publication, Fujimoto et al. investigated impact of CCRT on PD-L1 expression from paired NSCLC specimens of patients that had been treated with CCRT followed by surgery. ${ }^{30} \mathrm{In}$ this study a total of 35 patients had sufficient material before and after CCRT for matched analysis. Of these, 22 patients had PD-L1 expression on tumour cells in the pre-CCRT specimens, and 21 patients had PD-L1 expression on tumour cells in the post-CCRT specimens. Overall, the percentage of tumour cells with PD-L1 expression significantly decreased between the pre- and post-CCRT specimens $(p=0.024)$. Sixteen patients had decreased, 15 unchanged and 4 increased PD-L1 expression after CCRT compared with that before CCRT. Of the 15 patients with unchanged PD-L1 expression, PD-L1 expression was negative in pre- and remained in post-CCRT specimens in 11 patients. PD-L1 expression in pre- and post CCRT tumour material was not significantly associated with OS, howev- er they found significant association between the change in PD-L1 expression and survival time. The median OS of patients with decreased, unchanged, or increased PD-L1 expression was 85.1, 92.8 and 14.6 months, respectively $(\mathrm{p}<0.001)$. They also found that the stromal CD8+ lymphocytes density increased after CCRT. They observed that patients with intermediate or high stromal CD8+ lymphocytes density in the pre- or post- CCRT material tended to have longer OS. In other studies, increased PD-L1 expression and increased number of tumour-infiltrating lymphocytes were associated with better response to PD-1/PD-L1 inhibitors. These data could be beneficial in the future for selection of appropriate patients and planning the optimal time for incorporation of immunotherapy in treatment of locally advanced NSCLC, but more data are needed for final conclusions.

All these data suggest that radiation will play an important role in the treatment of LA-NSCLC also in the future, but will be combined with new therapies such as immunotherapy. RT can act as a stimulus of the immune system with the enhanced release of tumour antigens, followed by activation and migration of dendritic cells and cross-presentation of tumour antigens that resulted in tumour specific T-cell activation and proliferation. On the other hand, PD-1/PD-L1 antibodies by blocking inhibitory signalling pathways on infiltrating $\mathrm{T}$ cells act as the immune system modulator on the side of subsequent immune response that can synergistically contribute to more definitive and durable both systemic and local anti-tumour action than either approach alone.

\section{Conclusions}

Long-term treatment results with CCRT for patients with LA-NSCLC in our analysis showed 10-year survival rate of $11.2 \%$, which are comparable to published data though far from satisfactory. New treatment strategies are investigated to improve these results including treatment with check-point inhibitors. Evaluation of OS with regard to pretreatment PD-L1 status in our analysis showed that patients with PD-L1 expression had significant lower OS. This data suggest that immune system play an important role in the regulation of antitumour response to treatment.

Radiation dose, fractionation schedules and the optimal timing of immunotherapy for optimal synergy between RT and immunotherapy are the field for the future investigation. 


\section{References}

1. Zadnik V, Primic Zakelj M, Lokar K, Jarm K, Ivanus U, Zagar T, et al. Cancer burden in Slovenia with the time trends analysis. Radiol Oncol 2017; 51: 47-55. doi: 10.1515/raon-2017-0008

2. Aupérin $A$, Le Péchoux $C$, Rolland E, Curran WJ, Furuse $K$, Fournel $P$, et al. Meta-analysis of concomitant versus sequential radiochemotherapy in locally advanced non-small-cell lung cancer. J Clin Oncol 2010; 28: 2181-90. doi: $10.1200 / J C O .2009 .26 .2543$

3. Pless $M$, Stupp R, Ris H-B, Stahel RA, Weder W, Thiersteinet $S$, et al. Induction chemoradiation in stage IIIA/N2 non-small-cell lung cancer: a phase 3 randomised trial. Lancet 2015; 386: 1049-56. doi: 10.1016/S01406736(15)60294-X

4. Eberhardt WEE, Pöttgen C, Gauler TC, Friedel G, Veit S, Heinrichet V, et al. Phase III study of surgery versus definitive concurrent chemoradiotherapy boost in patients with resectable stage IIIA(N2) and selected IIIB non-smallcell lung cancer after induction chemotherapy and concurrent chemoradiotherapy (ESPATUE). J Clin Oncol 2015; 33: 4194-201. doi: 10.1200/ JCO.2015.62.6812

5. Bradley JD, Paulus R, Komaki R, Masters G, Blumenscheinet G, Schild S, et al. Standard-dose versus high-dose conformal radiotherapy with concurrent and consolidation carboplatin plus paclitaxel with or without cetuximab for patients with stage IIIA or IIIB non-small-cell lung cancer (RTOG 0617): a randomised, two-by-two factorial p. Lancet Oncol 2015; 16: 187-99. doi: 10.1016/S1470-2045(14)71207-0

6. Garon EB, Naiyer AR, Hui R, Leighl N, Balmanoukian AS, Eder JP, et al. Pembrolizumab for the treatment of non-small-cell lung cancer. $N$ Engl J Med 2015; 372: 2018-28. doi: 10.1056/NEJMoa1501824

7. Brahmer J, Reckamp KL, Baas P, Crinò L, Eberhardt WEE, Poddubskaya E, et al. Nivolumab versus docetaxel in advanced squamous-cell non-small-cell lung cancer. N Engl J Med 2015; 373: 123-35. doi: 10.1056/NEJMoa1504627

8. Reck $M$, Rodríguez-Abreu $D$, Robinson $A G$, Hui $R$, Csőszi $T$, Fülöp $A$, et al. Pembrolizumab versus chemotherapy for PD-L1-positive nonsmall-cell lung cancer. N Engl J Med 2016; 375: 1823-33. doi: 10.1056/ NEJMoa1606774

9. Shaverdian N, Lisberg AE, Bornazyan K, Veruttipong D, Goldman JW, Formenti SC, et al. Previous radiotherapy and the clinical activity and toxicity of pembrolizumab in the treatment of non-small-cell lung cancer: a secondary analysis of the KEYNOTE-001 phase 1 trial. Lancet Oncol 2017; 18: 895-903. doi: 10.1016/S1470-2045(17)30380-7

10. Antonia SJ, Villegas A, Daniel D, Vicente D, Murakami S, Hui R, et al. Durvalumab after chemoradiotherapy in stage III non-small-cell lung cancer. N Engl J Med 2017; 377: 1919-29. doi: 10.1056/NEJMoa1709937

11. Albain KS, Crowley JJ, Turrisi AT, Gandara DR, Farrar WB, Clark Jl, et al. Concurrent cisplatin, etoposide, and chest radiotherapy in pathologic stage IIIB non-small-cell lung cancer: a southwest oncology group phase II study, SWOG 9019. J Clin Oncol 2002; 20: 3454-60. doi: 10.1200/JCO.2002.03.055

12. National Institute of Cancer. Common terminology criteria for adverse events (CTCAE) common terminology criteria for adverse events v3.0 (CTCAE). [cited 2017 Nov 2]. Available at http://ctep.cancer.gov/protocolDevelopment/ electronic applications/docs/ctcaev3.pdf. NIH Publ 2010; 2009: 0-71. doi: 10.1080/00140139.2010.489653

13. Therasse P, Arbuck SG, Eisenhauer EA, Wanders J, Kaplan RS, Rubinstein L, et al. New guidelines to evaluate the response to treatment in solid tumors. JNCI 2000; 92: 205-16. doi: 10.1093/jnci/92.3.205

14. Vrankar M, Zwitter M, Kern I, Stanic K. PD-L1 expression can be regarded as prognostic factor for survival of non-small cell lung cancer patients after chemoradiotherapy. Neoplasma 2018; 59: 101-6. doi: 10.4149/ neo_2018_170206N77

15. Albain KS, Swann RS, Rusch VW, Turrisi AT, Shepherd FA, Smith C, et al. Radiotherapy plus chemotherapy with or without surgical resection for stage III non-small-cell lung cancer: a phase III randomised controlled trial. Lancet 2009; 374: 379-86. doi: 10.1016/S0140-6736(09)60737-6

16. Postmus PE, Kerr KM, Oudkerk M, Senan S, Waller DA, Vansteenkiste J, et al. Early and locally advanced non-small-cell lung cancer (NSCLC): ESMO Clinical Practice Guidelines for diagnosis, treatment and follow-upt. Ann Oncol 2017; 28 (Suppl 4): iv1-21. doi: 10.1093/annonc/mdx222

17. Kovač V, Smrdel U. Meta-analyses of clinical trials in patients with non-small cell lung cancer. Neoplasma 2004; 51: 334-40.
18. Tsujino K, Kurata T, Yamamoto S, Kawaguchi T, Kubo A, Isa S, et al. Is consolidation chemotherapy after concurrent chemo-radiotherapy beneficial for patients with locally advanced non-small-cell lung cancer?: A pooled analysis of the literature. J Thorac Oncol 2013; 8: 1181-9. doi: 10.1097/ JTO.0b013e3182988348

19. Luo $H$, Yu X, Liang N, Xie J, Deng G, Liu Q, et al. The effect of induction chemotherapy in patients with locally advanced nonsmall cell lung cancer who received chemoradiotherapy. Medicine 2017; 96: e6165. doi: 10.1097/ MD.0000000000006165

20. Kelly K, Chansky K, Gaspar LE, Albain KS, Jett J, Ung YC, et al. Phase III trial of maintenance gefitinib or placebo after concurrent chemoradiotherapy and docetaxel consolidation in inoperable stage III non-small-cell lung cancer: SWOG S0023. J Clin Oncol 2008; 26: 2450-6. doi: 10.1200/JCO.2007.14.4824

21. Wozniak AJ, Moon J, Thomas CR, Kelly K, Mack PC, Gaspar LE, et al. A pilot trial of cisplatin/etoposide/radiotherapy followed by consolidation docetaxel and the combination of bevacizumab (NSC-704865) in patients with inoperable locally advanced stage III non-small-cell lung cancer: SWOG S0533. Clin Lung Cancer 2015; 16: 340-7. doi: 10.1016/j.cllc.2014.12.014

22. Zeng J, See AP, Phallen J, Jackson CM, Belcaid Z, Ruzevick J, et al. Anti-pd-1 blockade and stereotactic radiation produce long-term survival in mice with intracranial gliomas. Int J Radiat Oncol 2013; 86: 343-9. doi: 10.1016/j. ijrobp.2012.12.025

23. Deng L, Liang H, Burnette B, Beckett M, Darga T, Weichselbaum RR, et al. Irradiation and anti-PD-L1 treatment synergistically promote antitumor immunity in mice. J Clin Invest 2014; 124: 687-95. doi: 10.1172/JCI67313

24. Dovedi SJ, Adlard AL, Lipowska-Bhalla G, McKenna C, Jones S, Cheadle $\mathrm{EJ}$, et al. Acquired resistance to fractionated radiotherapy can be overcome by concurrent PD-L1 blockade. Cancer Res 2014; 74: 5458-68. doi: 10.1158/0008-5472.CAN-14-1258

25. Sharabi AB, Lim M, DeWeese TL, Drake CG. Radiation and checkpoint blockade immunotherapy: Radiosensitisation and potential mechanisms of synergy. Lancet Oncol 2015; 16: e498-509. doi: 10.1016/S1470-2045(15)000078

26. Park SS, Dong H, Liu X, Harrington SM, Krco CJ, Grams MP, et al. PD-1 restrains radiotherapy-induced abscopal effect. Cancer Immunol Res 2015; 3: 610-9. doi: 10.1158/2326-6066.CIR-14-0138

27. Lumniczky K, Sáfrány $G$. The impact of radiation therapy on the antitumor immunity: local effects and systemic consequences. Cancer Lett 2015; 356: 114-25. doi: 10.1016/j.canlet.2013.08.024

28. Demaria S, Golden EB, Formenti SC. Role of local radiation therapy in cancer immunotherapy. JAMA Oncol 2015; 1: 1325. doi: 10.1001/jamaoncol.2015.2756

29. Derer A, Frey B, Fietkau R, Gaipl US. Immune-modulating properties of ionizing radiation: rationale for the treatment of cancer by combination radiotherapy and immune checkpoint inhibitors. Cancer Immunol Immunother 2016; 65: 779-86. doi: 10.1007/s00262-015-1771-8

30. Fujimoto D, Uehara K, Sato Y, Sakanou I, Ito M, Teraoka S, et al. Alteration of PD-L1 expression and its prognostic impact after concurrent chemoradiation therapy in non-small cell lung cancer patients. Sci Rep 2017; 7: 11373. doi: 10.1038/s41598-017-11949-9

31. Hallahan D, Kuchibhotla J, Wyble C. Cell adhesion molecules mediate radiation-induced leukocyte adhesion to the vascular endothelium. Cancer Res 1996; 56: 5150-5.

32. Sharabi AB, Nirschl CJ, Kochel CM, Nirschl TR, Francica BJ, Velarde E, et al. Stereotactic radiation therapy augments antigen-specific PD-1-mediated antitumor immune responses via cross-presentation of tumor antigen. Cancer Immunol Res 2015; 3: 345-55. doi: 10.1158/2326-6066.CIR-14-0196

33. Kachikwu EL, Iwamoto KS, Liao Y-P, DeMarco JJ, Agazaryan N, Economou J, et al. Radiation enhances regulatory T cell representation. Int J Radiat Oncol 2011; 81: 1128-35. doi: 10.1016/j.jijrobp.2010.09.034

34. Reits EA, Hodge JW, Herberts CA, Groothuis TA, Chakraborty M, K.Wansley $\mathrm{E}$, al. Radiation modulates the peptide repertoire, enhances MHC class expression, and induces successful antitumor immunotherapy. J Exp Med 2006; 203: 1259-71. doi: 10.1084/jem.20052494

35. Vanpouille-Box C, Diamond JM, Pilones KA, Zavadil J, Babb JS, Formenti,SC et al. TGF is a master regulator of radiation therapy-induced antitumor immunity. Cancer Res 2015; 75: 2232-42. doi: 10.1158/0008-5472.CAN14-3511 
36. Velcheti V, Schalper Ka, Carvajal DE, Anagnostou VK, Syrigos KN, Sznol M, et al. Programmed death ligand-1 expression in non-small cell lung cancer. Lab Investig 2014; 94: 107-16. doi: 10.1038/labinvest.2013.130

37. Cooper WA, Tran T, Vilain RE, Madore J, Selinger Cl, Kohonen-Corish $\mathrm{M}$, et al. PD-L1 expression is a favorable prognostic factor in early stage non-small cell carcinoma. Lung Cancer 2015; 89: 181-8. doi: 10.1016/j. lungcan.2015.05.007

38. Wang A, Wang HY, Liu Y, Zhao MC, Zhang HJ, Lu ZY, et al. The prognostic value of PD-L1 expression for non-small cell lung cancer patients: a metaanalysis. Eur J Surg Oncol 2015; 41: 450-6. doi: 10.1016/j.ejso.2015.01.020

39. Zhou Z, Zhan P, Song Y. PD-L1 over-expression and survival in patients with non-small cell lung cancer: a meta-analysis. Transl Lung Cancer Res 2015; 4: 203-2082015; 4: 203-8. doi: 10.3978/j.issn.2218-6751.2015.03.02

40. Herbst RS, Soria J, Kowanetz M, Fine GD, Hamid O, Gordon MS, et al Predictive correlates of response to the anti-PD-L1 antibody MPDL3280A in cancer patients. Nature 2014; 515: 563-7. doi: 10.1038/nature14011 